\title{
The efficacy of a thrombin-based hemostatic agent in primary total knee arthroplasty: a meta-analysis
}

\author{
Chen Wang ${ }^{1,2 \dagger}$, Zhe Han ${ }^{3}$, Tao Zhang ${ }^{4}$, Jian-xiong Ma ${ }^{1 \dagger}$, Xuan Jiang ${ }^{1}$, Ying Wang ${ }^{1}$ and Xin-long Ma ${ }^{1 *}$
}

\begin{abstract}
Purpose: Total knee arthroplasty (TKA) is a popular procedure in severe osteoarthritis. But perioperative bleeding remains a problem. Flosea ${ }^{\circledR}$ is a mixture of thrombin and bovine gelatin which can benefit a lot on reducing intraoperative and postoperative bleeding. However, there is no enough evidence judging its safety and efficiency. So a meta-analysis is conducted by us to evaluate the efficacy and safety of a thrombin-based hemostatic agent compared with conventional methods in TKA.

Method: Two independent reviewers selected literatures published before August 2014 from MEDLINE, Embase, and The Cochrane Central Register of Controlled Trials. Other internet databases were also performed to identify trials according to the Cochrane Collaboration guidelines. High-quality randomized controlled trials (RCTs), prospective control trials (PCTs), and case controlled trials (CCTs) were selected. The meta-analysis was undertaken using RevMan 5.1 for Windows.

Results: Three RCTs, one PCT, and one CCT met the inclusion criteria. There were significant differences in hemoglobin decline and calculated total blood loss between the Floseal ${ }^{\circledR}$ group and control group. There were no significant differences in postoperative drainage volume, rate of transfusion requirement, incidence of wound infection, deep vein thrombosis (DVT), and pulmonary embolism (PE) between treatment and control groups.

Conclusions: The present meta-analysis indicates that a thrombin-based hemostatic agent can reduce hemoglobin decline and calculated total blood loss after TKA and is not related to adverse reactions or complications such as wound infection, DVT, and PE.
\end{abstract}

Keywords: Floseal ${ }^{\oplus}$, Thrombin, Arthroplasty, Meta-analysis

\section{Introduction}

Total knee arthroplasty (TKA) has become a common treatment for severe knee arthritis [1]. However, because of extensive soft tissue dissection, long operative time, and a large amount of bone cutting, patients undergoing primary TKA are particularly prone to large intraoperative and postoperative blood loss which may lead to morbidity including pain, decrease range of motion, and delayed recovery. Although various methods have been taken by surgeons to reduce blood loss including electrocoagulation, cell salvage, predonated autologous blood

\footnotetext{
* Correspondence: 2008021123@tijmu.edu.cn

${ }^{\dagger}$ Equal contributors

'Biomechanics Labs of Orthopaedics Institute, Tianjin Hospital, Tianjin 300050, People's Republic of China

Full list of author information is available at the end of the article
}

transfusion, hemostatic agents, erythropoietic agents, and minimally invasive surgery, many patients still need blood transfusion for significant blood loss [2]. Besides, fibrinolysis reaction activated by surgical injury and ischemia reperfusion after tourniquet deflation contribute to the blood loss [3,4].

Allogenic blood transfusion may be related to systemic complications such as anaphylactic reaction, immunological rejection, hemolytic reaction, infectious disease, and metabolic disorders prolonging the duration of hospitalization and causing serious social economic burden [5]. So it is crucial to minimize the bleeding and transfusion requirements for the patients undergoing TKA.

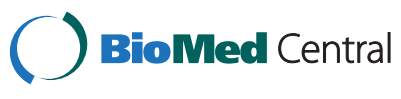

(c) 2014 Wang et al.; licensee BioMed Central Ltd. This is an Open Access article distributed under the terms of the Creative Commons Attribution License (http://creativecommons.org/licenses/by/4.0), which permits unrestricted use, distribution, and reproduction in any medium, provided the original work is properly credited. The Creative Commons Public Domain Dedication waiver (http://creativecommons.org/publicdomain/zero/1.0/) applies to the data made available in this article, unless otherwise stated. 


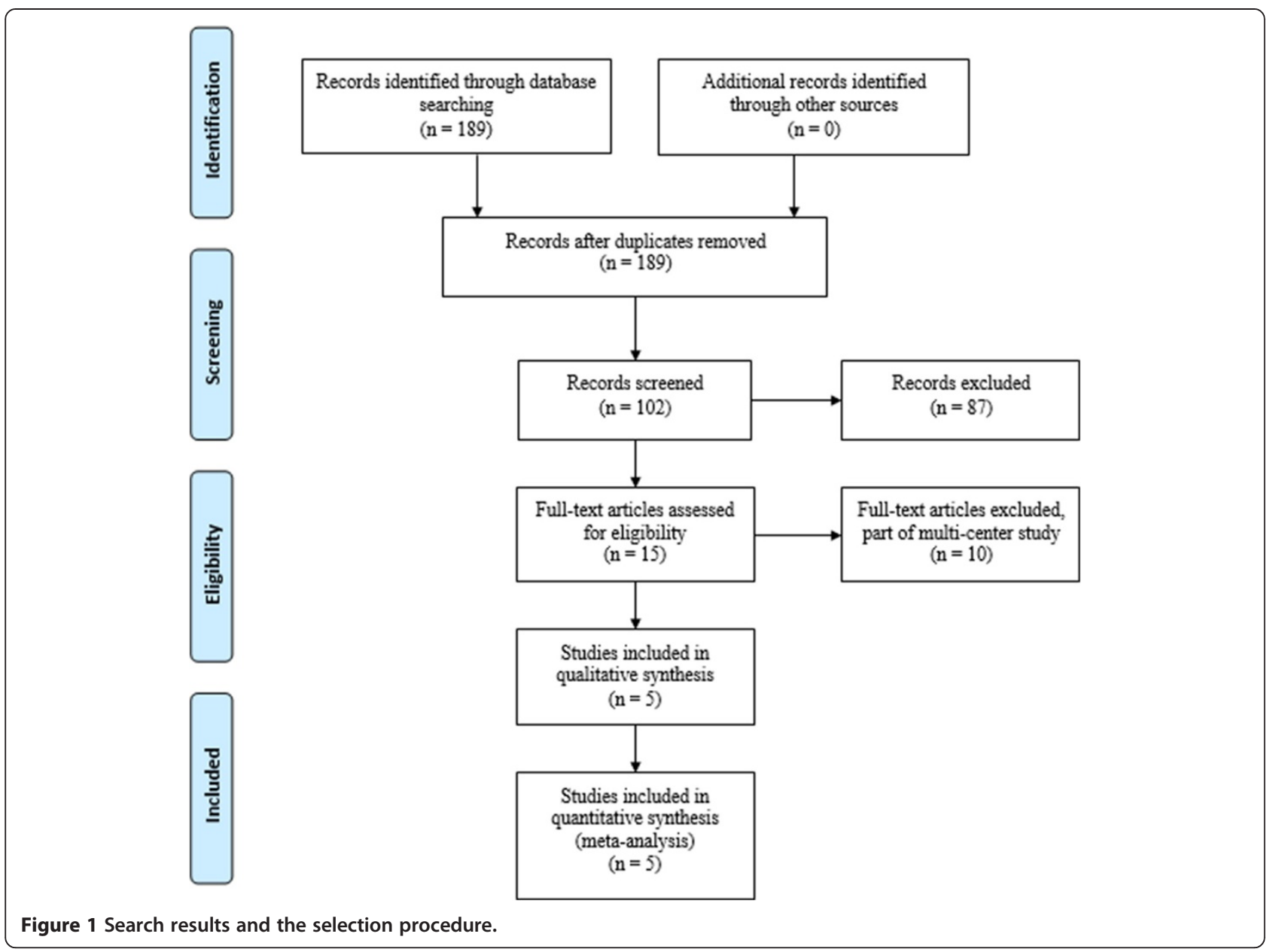

Hemostatic agent Floseal $^{\bullet}$ is a mixture of thrombin and bovine gelatin [6] which can benefit a lot on reducing intraoperative and postoperative bleeding and transfusion requirements. Thrombin-based hemostatic agents have come out nearly 15 years and were widely used in surgical procedure including gynecology, general surgery, and orthopedics which were still attracting the attention and interest of multitudinous surgeons. Clapp M [7] found Floseal $^{\circ}$ can achieve hemostasis during a laparoscopic salpingotomy and preserve tubal patency.
Testini M [8] considered that Floseal $^{\bullet}$ was an effective additional agent compared with conventional hemostatic procedures in thyroid surgery. A number of clinical trials have been made to evaluate the efficacy and safety of the hemostatic matrix in primary TKA. However, some have been criticized for poor designs, inaccurate evaluations, inconclusive results, and short-term follow-ups. Therefore, we conducted a meta-analysis, pooling the data from randomized controlled trials (RCTs) and non-RCTs to provide an evidence-based judgment regarding the

Table 1 Cohort characteristics

\begin{tabular}{|c|c|c|c|c|c|c|c|}
\hline Studies & $\begin{array}{l}\text { Cases } \\
(\mathrm{F} / \mathrm{C})\end{array}$ & $\begin{array}{l}\text { Mean age } \\
(\mathrm{F} / \mathrm{C})\end{array}$ & $\begin{array}{l}\text { Male patient } \\
(\mathrm{F} / \mathrm{C})\end{array}$ & $\begin{array}{l}\text { Dosage } \\
(\mathrm{ml})\end{array}$ & $\begin{array}{l}\text { Prophylactic } \\
\text { antithrombotic }\end{array}$ & $\begin{array}{l}\text { Reference } \\
\text { type }\end{array}$ & $\begin{array}{l}\text { Quality assessment } \\
\text { score }\end{array}$ \\
\hline Kim 2012 [11] & 97/99 & $72.7 / 70.1$ & NS & 10 & Aspirin or warfarin, NS & $\mathrm{RCT}$ & 6 \\
\hline Francesco 2013 [9] & $51 / 42$ & $67.9 / 70.2$ & 24/17 & 10 & LMWH 4,000 IU & $\mathrm{RCT}$ & 4 \\
\hline Suarez 2014 [10] & $56 / 52$ & $65.9 / 65.1$ & $20 / 21$ & 10 & Enoxaparin, NS & $\mathrm{RCT}$ & 6 \\
\hline Helito 2013 [12] & $10 / 10$ & $67.8 / 66.6$ & NS & NS & Enoxaparin 40 mg & PCT & 17 \\
\hline $\begin{array}{l}\text { Comadoll } 2012 \\
\text { [13] }\end{array}$ & $\begin{array}{l}184 / \\
165\end{array}$ & NS & $64 / 54$ & 20 & Warfarin 5 mg & $\mathrm{CCT}$ & 18 \\
\hline
\end{tabular}

F Floseal $^{\oplus}, \mathrm{C}$ control, $L M W H$ low molecular weight heparin, NS not stated. 


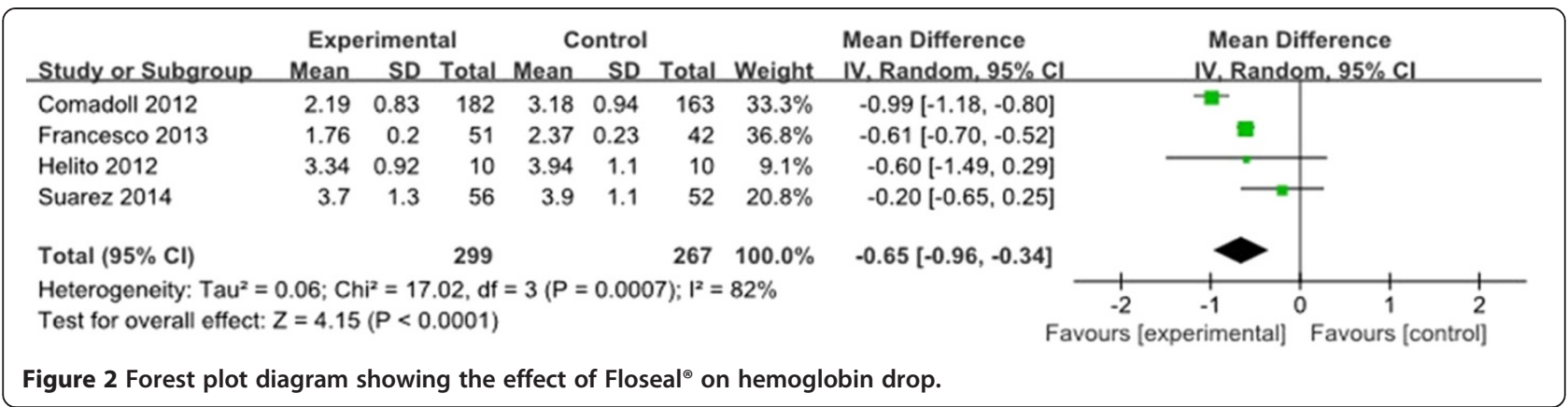

use of a thrombin-based hemostatic agent in patients undergoing primary TKA.

\section{Methods}

\section{Search strategy}

We conducted a meta-analysis to identify academic articles from electronic databases, including MEDLINE (1966 to August 2014), Embase (1980 to August 2014), and The Cochrane Central Register of Controlled Trials. Other internet databases were also performed to identify trials according to the Cochrane Collaboration guidelines. There were no language restrictions. The search strategy is presented in Figure 1. It included only studies conducted on human subjects. In addition, using the Google search engine, the same search terms were manually searched to find any further relevant studies that may have been missed in the database search. We used the following key words: "knee replacement OR arthroplasty" and "thrombin" in combination with Boolean operators AND or OR.

\section{Selection criteria and quality assessment}

We included all published RCTs and non-RCTs comparing Floseal ${ }^{\odot}$ with a control (placebo or nothing) in patients undergoing primary TKA. The methodological quality of the included studies was assessed by the review authors using a modification of the generic evaluation tool used by the Cochrane Bone, Joint and Muscle Trauma Group. To provide a qualification of a bias risk, quality criteria included (i) details of randomization method, (ii) allocation

Table 2 Subgroup analysis of postoperative hemoglobin decline

\begin{tabular}{lllllll}
\hline $\begin{array}{l}\text { Outcome or } \\
\text { subgroup }\end{array}$ & Studies & \multicolumn{6}{l}{ Effect estimate } & & \\
\hline & & $X^{2}$ & $R^{2}(\%)$ & $M D$ & $95 \% \mathrm{Cl}$ & $P$ value \\
$\begin{array}{l}\text { Cemented } \\
\text { prosthesis }\end{array}$ & 3 & 10.31 & 81 & -0.62 & {$[-1.22,-0.03]$} & 0.006 \\
$\begin{array}{l}\text { Total dose }= \\
10 \mathrm{ml}\end{array}$ & 3 & 3.03 & 34 & -0.52 & {$[-0.77,-0.26]$} & 0.22 \\
$\begin{array}{l}\text { Duration of } \\
\text { drainage }\end{array}$ & 3 & 3.03 & 34 & -0.52 & & \\
\hline
\end{tabular}

concealment, (iii) blinding of participants and personnel, (iv) blind outcome assessment, (v) incomplete outcome data, (vi) selective outcome reporting, and (vii) other sources of bias.

\section{Data extraction}

For each eligible study, two of the authors independently extracted all the relevant data. Disagreement was resolved by a discussion with the third reviewer. Whenever necessary, we contacted the authors of the studies for missing data or further information. The following data were extracted: (1) demographic data of participants; (2) indication for TKA; (3) wound infection (superficial or deep), hematoma, wound dehiscence, limb swelling, bleeding from the wound, and reoperation because of a woundhealing complication; (4) postoperative blood transfusion, decrease in hemoglobin or hematocrit, thromboembolic complications, patient discomfort, and costs; (5) functional outcomes such as time to regain mobility; and (6) any other outcomes as mentioned in individual studies were considered for inclusion. In studies in which data were incomplete or unclear, attempts were made to contact investigators for clarification.

\section{Data analysis and statistical methods}

The meta-analysis was undertaken using RevMan 5.1 for Windows (The Cochrane Collaboration, Oxford, United Kingdom). We assessed statistical heterogeneity for each study with the use of a standard chi-square test (for heterogeneity, a level of $P<0.1$ was considered significant) and the $I^{2}$ statistic. An $I^{2}$ statistic value of $50 \%$ was considered to indicate substantial heterogeneity. The origins of heterogeneity, if present, were analyzed according to differences in methodological quality, characteristics of participants, and intervention. When the data allowed, the authors of this paper performed subgroup analysis of the trials. In comparing trials showing heterogeneity, pooled data were meta-analyzed using a random-effects model. Otherwise, a fixed-effects model was used for the analysis. Relative risks (or risk differences) and 95\% confidence intervals (CIs) were calculated for dichotomous 


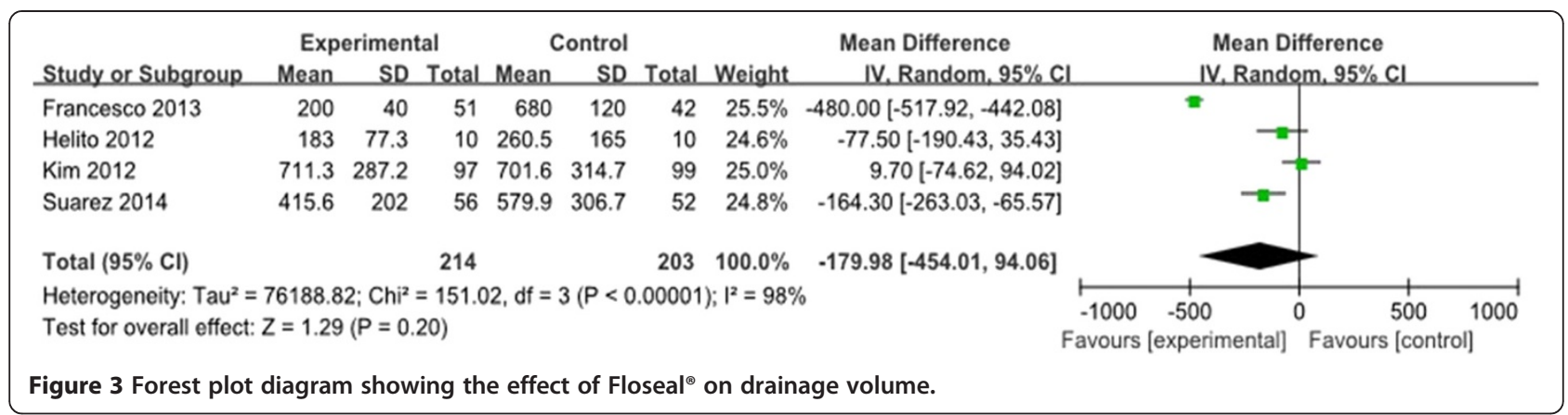

outcomes and mean differences (MDs) and 95\% CIs for continuous outcomes.

\section{Result}

\section{Search result}

We identified a total of 189 citations as potentially relevant. By screening the title and reading the abstract and the entire article, we found that three RCTs and two non-RCTs enrolling a total of 766 knees at a final follow-up were eligible for data extraction and metaanalysis [9-13]. The patients' characteristics were presented in Table 1. The sample size for each study ranged from 20 to 349 . Jadad scale is used to evaluate the quality of RCTs while MINORS assessment is used for non-RCTs. The quality of the literature is relatively high. But there are still some methodological limitations in RCTs. All the RCTs [9-11] reported that randomization was conducted through a computerassisted program. A double-blind methodology was reported in two RCTs $[10,11]$. None of the RCTs suggest a methodology for the blinding assessors. All of the studies provided results for a minimum of $95 \%$ of the included patients. Most of the patients who managed to undergo primary TKA suffered from osteoarthritis. Kim and Comadoll $[11,13]$ reported that all TKA were accomplished by the same doctor. Cemented prosthesis was used in four studies [10-13]. The other one used an uncemented prosthesis. Electrocautery hemostasis combined with a thrombin-based hemostatic agent was used in the treatment group in all the studies except one [12] which used an agent only. The control group received electrocautery hemostasis. Four literatures [9-12] mentioned volume of drainage in $24 \mathrm{~h}$ postoperatively. None of the studies reported whether drainage was clamped or not, while two studies $[10,11]$ stated the size and number of the drainage tube. Tourniquets were used in all the inclusive patients and were deflated after wound closure in three studies [9-11] and before wound closure in Comadoll's study. Helito did not provide this information while the pressure of the tourniquet was recorded (300 mmHg) [12]. Two studies [10,11] applied bandage after wound closure. Spinal anesthesia was performed in the study of Kim and Helito [11,12]. Others did not mention an anesthesia method. The dosage of Floseal ${ }^{\circ}$ ranged from 10 to $20 \mathrm{ml}, 10 \mathrm{ml}$ in three studies [9-11] and $20 \mathrm{ml}$ in Comadoll's trial. None of the studies used placebo in a control group. Four studies $[9,10,12,13]$ provided the indications of blood transfusion, which based on postoperative hemoglobin level, signs and symptoms of anemia such as hypotension, paleness, and tachycardia. Perioperative antithromboembolic prophylaxis therapy was performed in all the patients as followed in Table 1. The duration of a follow-up ranged from discharge to 6 weeks.

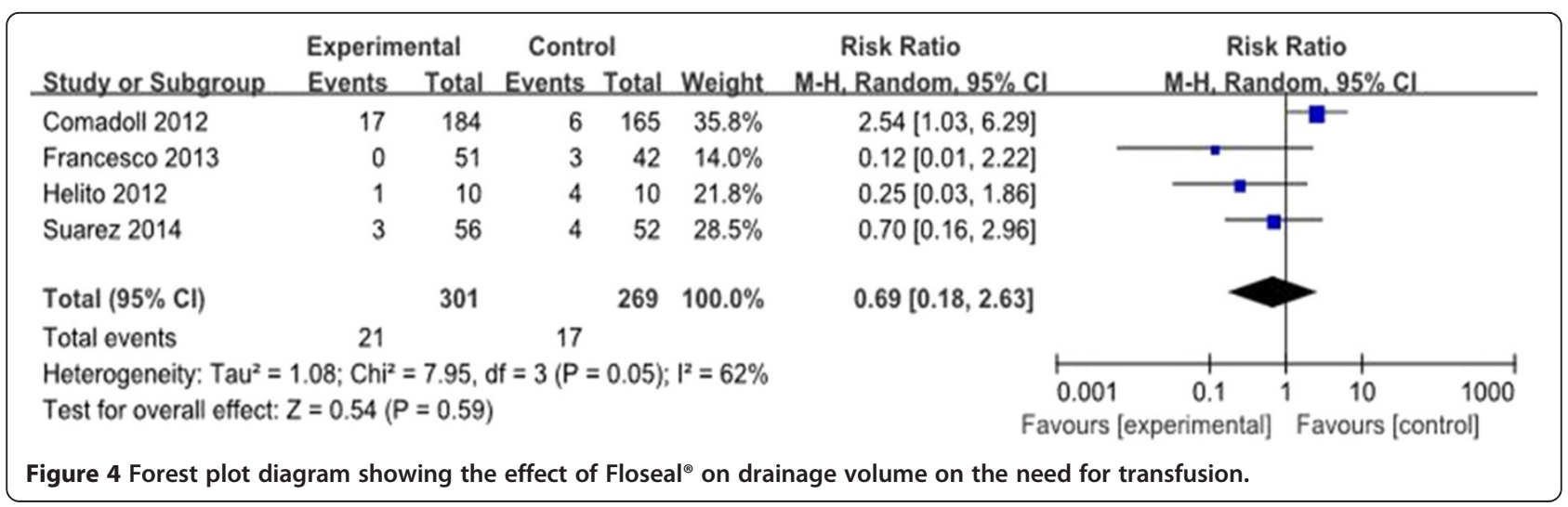




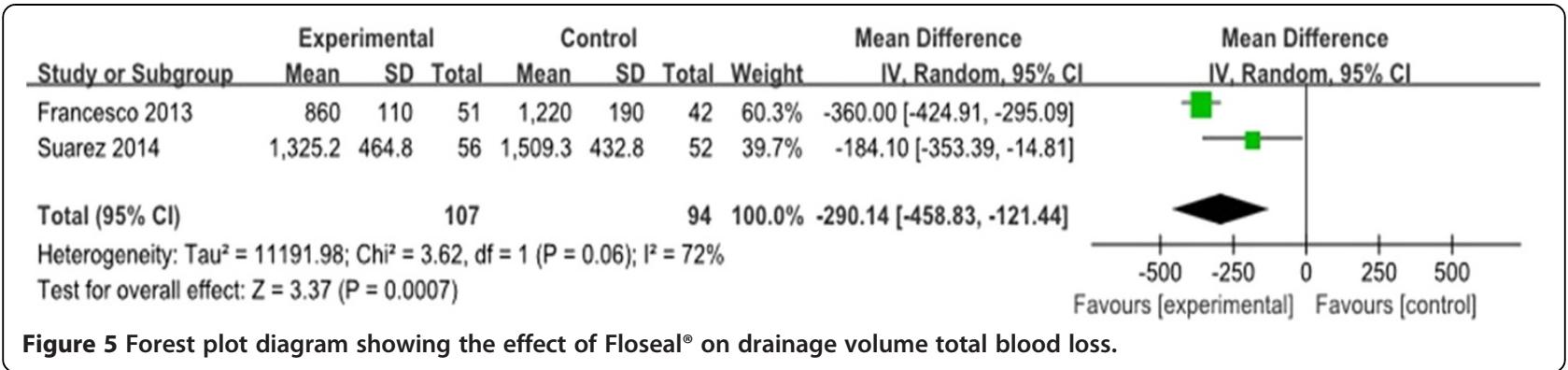

\section{Meta-analysis results \\ Hemoglobin decline}

We obtained usable data on hemoglobin drop from four trials including 566 knees $[9,10,12,13]$. As depicted in Figure 2, there was significant heterogeneity $\left(\chi^{2}=17.02\right.$, $\left.\mathrm{df}=3, \quad I^{2}=82 \%, \quad P=0.0007\right)$. Using a random-effects model, the pooled results indicated that there was significant difference between the groups in terms of hemoglobin drop (MD $=-0.65$, 95\% CI: -0.96 to $-0.34, P<0.0001)$. Subgroup analysis was performed for postoperative hemoglobin decline which showed that the existence of heterogeneity was due to the different doses of Floseal $^{\circledR}$ and duration of drainage (Table 2).

\section{Volume of drainage}

The volume of drainage was mentioned in four trials [9-12]. The pooled results showed significant heterogeneity $\left(\chi^{2}=151.02, \mathrm{df}=3, I^{2}=95 \%, P<0.00001\right.$; Figure 3$)$. Thus, a random-effects model was used. Meta-analysis showed no significant difference between the groups in terms of volume of drainage ( $\mathrm{MD}=-179.98$, 95\% CI: -454.01 to $94.06, P=0.20)$.

\section{Need for transfusion}

The need for transfusion was reported in four trials $[9,10,12,13]$. The pooled results showed no significant difference between the groups $(\mathrm{RR}=0.69,95 \% \mathrm{CI}$ : 0.18 to $2.63, P=0.05)$. There was significant heterogeneity $\left(\chi^{2}=7.95, \mathrm{df}=3, I^{2}=62 \%, P=0.05\right.$; Figure 4$)$. A randomeffects model was used.

\section{Total blood loss}

Total blood loss was documented in two studies $[9,10]$. The difference between the groups was significant $(\mathrm{MD}=-290.14,95 \% \mathrm{CI}:-458.83$ to $-121.44, P=0.0007$; Figure 5). A random-effects model was used because statistical heterogeneity was found between the studies $\left(\chi^{2}=3.62, \mathrm{df}=1, I^{2}=72 \%, P=0.06\right)$.

\section{Infection}

The incidence of infection was reported in three studies $[9,11,13]$. The pooled results indicated that the incidence of infection was $0.6 \%$ in the Floseal $^{\circ}$ group, compared with $0.13 \%$ in the conventional group. This difference was not significant $(\mathrm{RD}=-0.01,95 \% \mathrm{CI}$ : -0.02 to 0.01 , $P=0.45$; Figure 6). A fixed-effects model was used because no statistical heterogeneity was found between the studies $\left(\chi^{2}=2.67, \mathrm{df}=2, I^{2}=25 \%, P=0.26\right)$.

\section{Deep vein thrombosis (DVT)}

The incidence of DVT was reported in three trials $[9,11,13]$. The pooled results of the trials showed that the use of $\mathrm{Floseal}^{\circ}$ did not increase the risk of DVT. ( $\mathrm{RD}=0.00,95 \% \mathrm{CI}:-0.01$ to $0.02, P=0.67$ ). There was no significant heterogeneity $\left(\chi^{2}=0.64, \mathrm{df}=2, I^{2}=0 \%\right.$, $P=0.73$; Figure 7). A fixed-effects model was used.

\section{Pulmonary embolism (PE)}

The incidence of PE was mentioned in two trials $[9,13]$. The pooled results of the trials showed that the use of Floseal ${ }^{\circ}$ did not increase the risk of DVT. (RD $=0.00,95 \% \mathrm{CI}$ : -0.01 to $0.02, P=0.59$ ). There was no significant heterogeneity

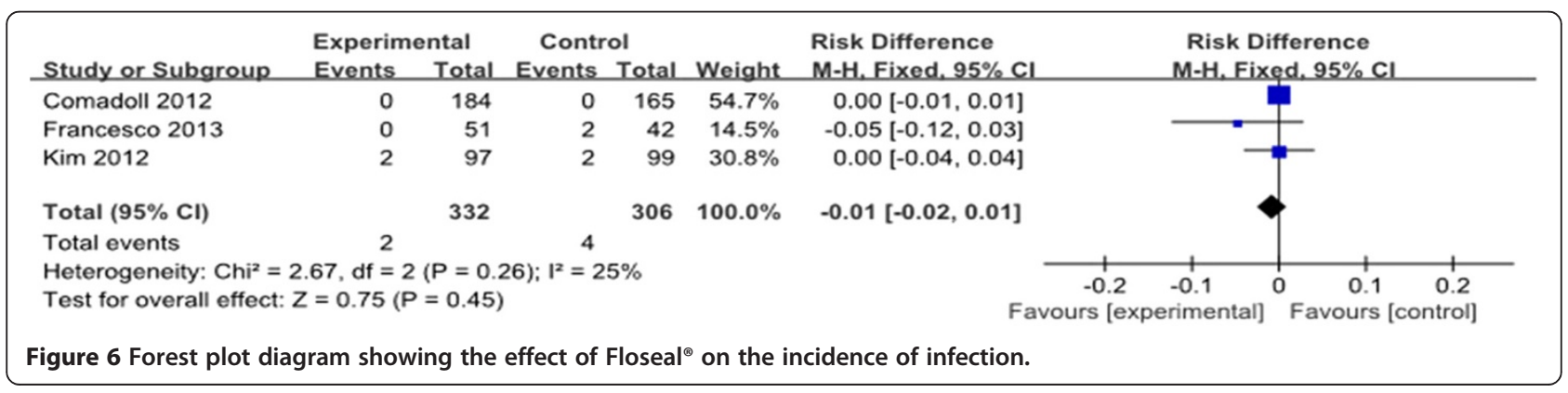




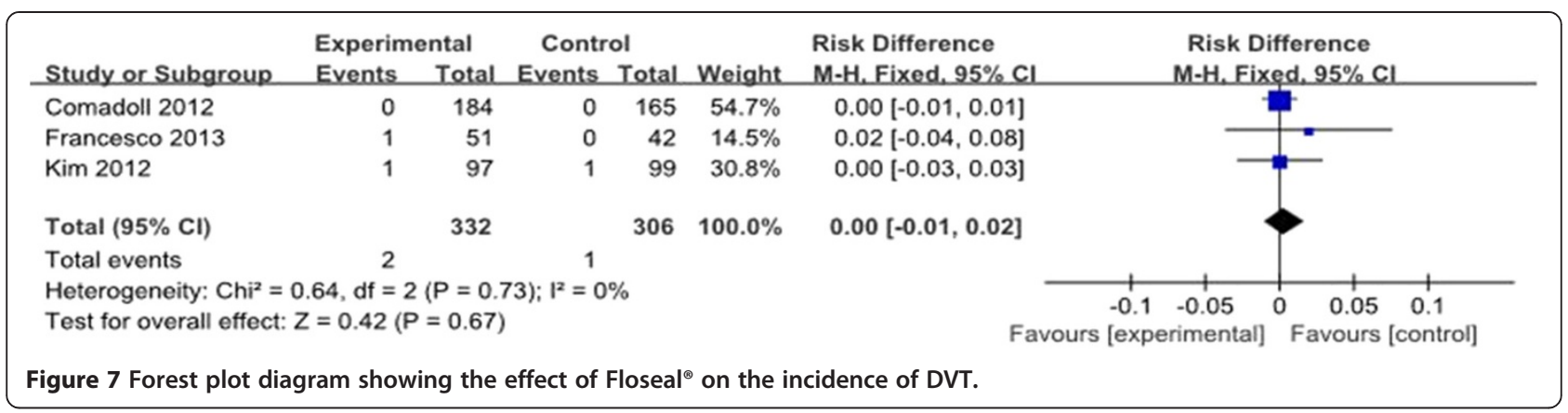

$\left(\chi^{2}=0.81, \mathrm{df}=1, I^{2}=0 \%, P=0.37\right.$; Figure 8$)$. A fixed-effects model was used.

\section{Other outcomes}

Several other outcome measures were identified, but insufficient data were provided for meta-analysis. For instance, Suarez found no significant differences in overall length of stay, hematocrit values, and postoperative fluids or hidden blood loss between two study groups [10]. There were no significant differences in colloid and crystalloid infusion between two groups in the study of Helito [12].

\section{Discussion}

The most important finding of the present meta-analysis was that the use of thrombin-based hemostatic agents can decrease the postoperative hemoglobin drop and total blood loss. Furthermore, no significant differences were found regarding to the risk of wound infection, DVT, and PE.

Three RCTs, one PCT, and one CCT met the inclusion criteria for the meta-analysis. All the RCTs stated that randomization was achieved by a computer-assisted program. The overall methodological quality of the included studies was relatively high. Two RCTs $[10,11]$ reported a methodology of double-blind, and no studies were provided to blind the assessors of group allocation so expectation bias and the potential for type II statistical error in their clinical outcomes may affect the analysis. All included studies had consistent baseline data, but none of them mentioned intention to treat analysis.
These methodological strengths and weaknesses should be considered when interpreting the findings of the present meta-analysis.

TKA is complicated by perioperative blood loss; $7.7 \%-$ $18.93 \%$ of the patients undertaking TKA need transfusion [14-17]. The present meta-analysis indicated that there was no significant difference in the rate of transfusion between two groups (6.98\% vs $6.32 \%)$. The reason could be an unmentioned transfusion trigger in the literature, different approach, and type of anesthesia in the surgical procedure. Besides various baselines of a preoperative hemoglobin level, different dosage and kinds of antithrombotic drugs between two groups also should be taken into consideration.

Four studies [9-12] mentioned postoperative volume of drainage. Our studies found no statistically significant differences between the treatment and control groups. Some literatures [12,13] did not provide the time of drainage discharge or the number of drainage tubes. What is more, varied methods of anesthesia and surgical approach may also affect the meta-analysis.

Anemia may lead to hypotension, cardiac failure, and even shock. Blood transfusion was needed to correct severe anemia. Four studies $[9,10,12,13]$ reported a postoperative hemoglobin decline. Two literatures $[9,10]$ mentioned total blood loss. The present meta-analysis showed significant differences in postoperative hemoglobin decline and total blood loss. Subgroup analysis showed the source heterogeneity for postoperative hemoglobin decline (Table 2). Extravasation into the tissues is the major hidden postoperative blood loss. While apparent postoperative

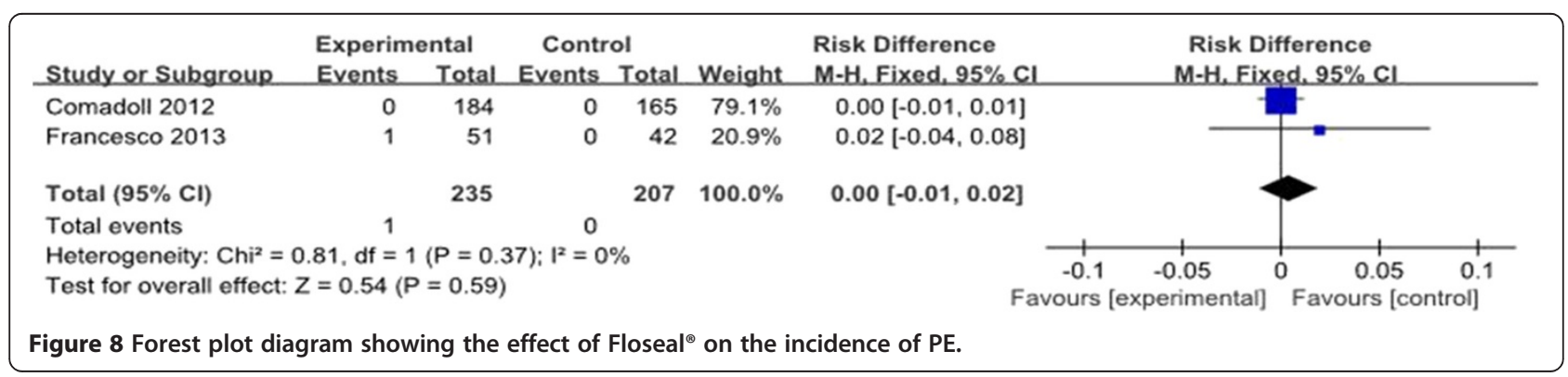


blood loss can be recorded through drainage bottles. From a present meta-analysis, we consider that the use of thrombin-based hemostatic agents can reduce hemoglobin drop and perioperative blood loss.

Infection is relatively rare after TKA but can be devastating in terms of morbidity and cost [18]. This metaanalysis found no significant difference in the incidence of infection, which was $0.6 \%$ with treatments and $0.13 \%$ in controls; the overall infection rate was $0.94 \%$. The reported incidence of infection after TKA ranged from $1 \%$ to $3 \%$ [19]. Because infection may also occur later, an assessment after a longer follow-up period may be required.

DVT is one of the common complications after TKA which may cause PE and even death [20]. Antithromboembolic prophylaxis therapy was adapted in all the inclusive patients, and there was no difference in the incidence of DVT $(0.6 \%$ vs $0.33 \%)$ or PE $(0.43 \%$ vs $0 \%)$ between the two groups.

There are several potential limitations of our metaanalysis. (1) Only five reports were included, and their sample sizes were relatively small, which may have affected our conclusions. (2) The follow-up of patients in some of the trials was unclear. Many patients were followed up in the short term. This may have resulted in underreporting of, for example, infection. (3) There were insufficient data to support analyses of length of stay, range of motion (ROM), postoperative fluids, and Visual Analog Scale Pain Score. (4) The existence of a publication bias also affects the analysis; it is a limitation in all meta-analysis. However, this is the first systematic review to evaluate safety and efficiency of thrombin-based hemostatic agents during TKA, by only including studies that have appropriate control and study groups. All of the included studies were of high quality. Further studies should be designed to explore an optimal dose and additional functions during the TKA based on high quality RCTs.

\section{Conclusion}

The present meta-analysis indicates that thrombin-based hemostatic agents can reduce hemoglobin decline and total blood loss after TKA and are not related to the adverse reactions or complications such as wound infection, DVT, and PE. In summary, the use of thrombin-based hemostatic agents is superior to standard electrocautery in patients undergoing primary TKA.

\section{Competing interests}

The authors declare that they have no competing interests.

\section{Authors' contributions}

XLM conceived of the design of the study. CW, ZH, and TZ performed the study, collected the data, and contributed to the design of the study. CW and ZH prepared the manuscript. JXM and YW edited the manuscript. All authors read and approved the final manuscript.
Authors' information

Chen Wang, M.D. was the first author.

\section{Acknowledgments}

The authors thank Dr De-wang Meng and Dr Ye Liu for their help with the language and are grateful for the support by the Wu Jie Ping Medical Foundation (no. 320.6750.11017) and the Tianjin Health Bureau Science and Technology Foundation (nos. 11KZ117 and 12KZ120).

\section{Author details}

${ }^{1}$ Biomechanics Labs of Orthopaedics Institute, Tianjin Hospital, Tianjin 300050, People's Republic of China. ${ }^{2}$ Tianjin Medical University, Tianjin 300070, People's Republic of China. ${ }^{3}$ Department of Orthopedics, Tianjin Hospital, Tianjin 300211, People's Republic of China. ${ }^{4}$ General Hospital of Tianjin Medical University, Tianjin 300052, People's Republic of China.

Received: 1 September 2014 Accepted: 22 September 2014

Published online: 15 October 2014

\section{References}

1. Kahn TL, Soheili A, Schwarzkopf R: Outcomes of total knee arthroplasty in relation to preoperative patient-reported and radiographic measures: data from the osteoarthritis initiative. Geriatr Orthop Surg Rehabil 2013, 4:117-126.

2. Conteduca F, Massai F, lorio R, Zanzotto E, Luzon D, Ferretti A: Blood loss in computer-assisted mobile bearing total knee arthroplasty. A comparison of computer-assisted surgery with a conventional technique. Int Orthop 2009, 33:1609-1613.

3. Charoencholvanich K, Siriwattanasakul P: Tranexamic acid reduces blood loss and blood transfusion after TKA: a prospective randomized controlled trial. Clin Orthop Relat Res 2011, 469:2874-2880.

4. Aglietti P, Baldini A, Vena LM, Abbate R, Fedi S, Falciani M: Effect of tourniquet use on activation of coagulation in total knee replacement. Clin Orthop Relat Res 2000, 371:169-177.

5. Bilgili MG, Erçin E, Peker G, Kural C, Başaran SH, Duramaz A, Avkan C: Efficiency and cost analysis of cell saver auto transfusion system in total knee arthroplasty. Balkan Med J 2014, 31:149-152.

6. Gazzeri R, Galarza M, Alfier A: Safety biocompatibility of gelatin hemostatic matrix (Floseal ${ }^{\oplus}$ and Surgiflo) in neurosurgical procedures. Surg Technol Int 2012, 22:49-54.

7. Clapp M, Huang JC: Use of floseal $^{\circledR}$ sealant in the surgical management of tubal ectopic pregnancy. Case Rep Obstet Gynecol 2013, 2013:906825

8. Testini M, Marzaioli R, Lissidini G, Lippolis A, Logoluso F, Gurrado A, Lardo D, Poli E, Piccinni G: The effectiveness of floseal ${ }^{\circledR}$ matrix hemostatic agent in thyroid surgery: a prospective, randomized, control study. Langenbecks Arch Surg 2009, 394:837-842

9. Di Francesco A, Flamini S, Fiori F: Hemostatic matrix effects on blood loss after total knee arthroplasty: a randomized controlled trial. Indian J Orthop 2013, 47:474-481.

10. Suarez JC, Slotkin EM, Alvarez AM, Szubski CR, Barsoum WK, Patel PD: Prospective, randomized trial to evaluate efficacy of a thrombin-based hemostatic agent in total knee arthroplasty. J Arthroplasty 2014, doi: 10.1016/j.arth.2014.05.025. [Epub ahead of print].

11. Kim HJ, Fraser MR, Kahn B, Lyman S, Figgie MP: The efficacy of a thrombinbased hemostatic agent in unilateral total knee arthroplasty: a randomized controlled trial. J Bone Joint Surg Am 2012, 94:1160-1165.

12. Helito CP, Gobbi RG, Castrillon LM, Hinkel BB, Pécora JR, Camanho GL: Comparison of Floseal ${ }^{\oplus}(r)$ and electrocautery in hemostasis after total knee arthroplasty. Acta Ortop Bras 2013, 21:320-322.

13. Comadoll JL, Comadoll S, Hutchcraft A, Krishnan S, Farrell K, Kreuwel HT, Bechter M: Comparison of hemostatic matrix and standard hemostasis in patients undergoing primary TKA. Orthopedics 2012, 35:e785-e793.

14. Frisch NB, Wessell NM, Charters MA, Yu S, Jeffries JJ, Silverton CD: Predictors and complications of blood transfusion in total Hip and knee arthroplasty. J Arthroplasty 2014, 29(9 Suppl):189-192.

15. Danninger T, Rasul R, Poeran J, Stundner O, Mazumdar M, Fleischut PM, Poultsides L, Memtsoudis SG: Blood transfusions in total hip and knee arthroplasty: an analysis of outcomes. ScientificWorldJournal 2014, 2014:623460.

16. Klika AK, Small TJ, Saleh A, Szubski CR, Chandran Pillai AL, Barsoum WK: Primary total knee arthroplasty allogenic transfusion trends, length of 
stay, and complications: nationwide inpatient sample 2000-2009. J Arthroplasty 2014, doi: 10.1016/j.arth.2014.06.018.

17. Yoshihara H, Yoneoka D: National trends in the utilization of blood transfusions in total Hip and knee arthroplasty. J Arthroplasty 2014, doi: 10.1016/j.arth.2014.04.029. [Epub ahead of print].

18. Derman PB, Kamath AF, Lee GC: Saline-coupled bipolar sealing in revision total knee arthroplasty for infection. Am J Orthop (Belle Mead NJ) 2013, 42:407-411.

19. Soriano A, Bori G, García-Ramiro S, Martinez-Pastor JC, Miana T, Codina C, Maculé F, Basora M, Martínez JA, Riba J, Suso S, Mensa J: Timing of antibiotic prophylaxis for primary total knee arthroplasty performed during ischemia. Clin Infect Dis 2008, 46:1009-1014.

20. Chotanaphuti T, Ongnamthip P, Songpatanasil T, Veerapan P, Deeprecha K Risk factors of deep vein thrombosis (DVT) after total knee arthroplasty (TKA) at Phramongkutklao Hospital. J Med Assoc Thai 2007, 90:485-491.

doi:10.1186/s13018-014-0090-7

Cite this article as: Wang et al:: The efficacy of a thrombin-based hemostatic agent in primary total knee arthroplasty: a meta-analysis. Journal of Orthopaedic Surgery and Research 2014 9:90.

\section{Submit your next manuscript to BioMed Central and take full advantage of:}

- Convenient online submission

- Thorough peer review

- No space constraints or color figure charges

- Immediate publication on acceptance

- Inclusion in PubMed, CAS, Scopus and Google Scholar

- Research which is freely available for redistribution 